\title{
Hector Ferral, Jonathan M. Lorenz: RadCases Interventional Radiology Second Edition
}

\author{
Thieme, New York, Stuttgart, Delhi, Rio de Janeiro, 2018, 253 p, format $21.8 \times 28 \mathrm{~cm}, 477$ \\ illustrations, ISBN 978-1-62623-282-2, e ISBN 978-1-62623-283-9
}

\section{Bruno Grignon ${ }^{1}$}

Received: 19 June 2018 / Accepted: 21 June 2018 / Published online: 28 June 2018

(c) Springer-Verlag France SAS, part of Springer Nature 2018

The aim of the "RadCases" series is to provide case-based radiology review books in all fields of medical imaging, using both printed material and electronic cases, to help the residents for their exams as well as for their daily practice. This volume is specifically devoted to the subspecialty of interventional radiology and offers 100 carefully selected and well-documented of vascular and nonvascular cases (plus additional 250 electronic cases available online).

The general organization of this book is similar to that of the other volumes of the series. On the right-hand page, the clinical presentation including one, two, three or four images (radiograph, arteriogram, computed tomography, magnetic resonance imaging and/or Doppler) is displayed. On the back of this page, imaging findings are discussed, the definitive diagnosis and differential diagnoses are presented, and essentials facts, as well as pearls and pitfalls, are highlighted. Case questions and answers are then proposed in a subsequent section. At the end of the book, a list of further readings (including one or two essential references) is proposed for each case. Finally, an alphabetical index allows referring primary diagnoses to case numbers.

In addition, the volume includes a code allowing 1 year of access to Thieme's online database of 350 cases (the 100 cases in the book plus additional 250 cases). As well as the other books of the RadCases series, it combines the portability of printed books with the interactive features of an electronic case-based format.
The authors are Hector Ferral and Jonathan M. Lorenz, respectively, Professor of Radiology, Section of Interventional Radiology, University of Chicago, Illinois, USA, and Senior Clinician Educator, Section of Interventional Radiology at NorthShore University HealthSystem, Evanston, Illinois, USA. This volume is the second edition of a previous one published in 2010, providing 100 new cases, and an additional case questions and answers section.

This work is attractive by its practical and pedagogical presentation. It offers on two pages the main imaging features, essential facts, pearls and pitfalls, differential diagnoses, with one or two references, covering the most common cases of interventional procedures. The critical remarks that could be made are the small size of several pictures, and the lack of logical order in the presentation of the cases.

Mainly devoted to residents in radiology, this book may also be of use to more experienced radiologists and other physicians dealing with interventional radiology.

Author contributions BG: manuscript writing and editing.

\section{Compliance with ethical standards}

Conflict of interest The author declares that he has no conflict of interest.
Bruno Grignon

b.grignon@chu-nancy.fr

1 University of Lorraine, CHU Nancy, Nancy, France 